\title{
Involvement of the end user: exploration of older people's needs and preferences for a wearable fall detection device - a qualitative descriptive study
}

This article was published in the following Dove Press journal:

Patient Preference and Adherence

20 December 2016

Number of times this article has been viewed

\author{
Friederike JS Thilo ${ }^{1,2}$ \\ Selina Bilger' \\ Ruud JG Halfens ${ }^{2}$ \\ Jos MGA Schols ${ }^{2,3}$ \\ Sabine Hahn'
}

'Applied Research and Development in Nursing, Health Division, Bern University of Applied Sciences, Bern, Switzerland; ${ }^{2}$ Department of Health Services Research, ${ }^{3}$ Department of Family Medicine, School CAPHRI, Maastricht University, Maastricht. the Netherlands
Correspondence: Friederike JS Thilo Applied Research and Development in Nursing, Health Division, Bern University of Applied Sciences, Murtenstrasse 10, 3008 Bern, Switzerland

$\mathrm{Tel}+4|3| 8484564$

Fax +4I 31848350 I

Email friederike.thilo@bfh.ch
Purpose: To explore the needs and preferences of community-dwelling older people, by involving them in the device design and mock-up development stage of a fall detection device, consisting of a body-worn sensor linked to a smartphone application.

Patients and methods: A total of 22 community-dwelling persons 75 years of age and older were involved in the development of a fall detection device. Three semistructured focus group interviews were conducted. The interview data were analyzed using qualitative descriptive analysis with deductive coding.

Results: The mock-up of a waterproof, body-worn, automatic and manual alerting device, which served both as a day-time wearable sensor and a night-time wearable sensor, was welcomed. Changes should be considered regarding shape, color and size along with alternate ways of integrating the sensor with items already in use in daily life, such as jewelry and personal watches. The reliability of the sensor is key for the participants. Issues important to the alerting process were discussed, for instance, who should be contacted and why. Several participants were concerned with the mandatory use of the smartphone and assumed that it would be difficult to use. They criticized the limited distance between the sensor and the smartphone for reliable fall detection, as it might restrict activity and negatively influence their degree of independence in daily life.

Conclusion: This study supports that involving end users in the design and mock-up development stage is welcomed by older people and allows their needs and preferences concerning the fall detection device to be explored. Based on these findings, the development of a "need-driven" prototype is possible. As participants are doubtful regarding smartphone usage, careful training and support of community-dwelling older people during real field testing will be crucial.

Keywords: focus group interview, coding, wearable device, sensor, mock-up, smartphone

\section{Introduction}

Population aging is a worldwide trend. ${ }^{1}$ The process of aging is accompanied by increasing health concerns, which have economic repercussions on the health care systems, including higher costs linked to the treatment of chronic illness. ${ }^{2-4}$ The promotion of a self-determined and safe lifestyle for citizens is a part of recent political strategies. ${ }^{5,6}$ These strategies entail promoting active aging in the home care setting ${ }^{7}$ and prioritizing living in the community instead of in long-term care facilities and are associated with lower costs. ${ }^{8}$ Living in the community is also the preference of older people. ${ }^{9}$

Experiencing a fall may, however, impede safe and active living. A fall is defined as "an unexpected event in which the participants come to rest on the ground, floor, 
or lower level." ${ }^{10} \mathrm{~A}$ fall is a serious health problem among the aging population. In persons aged 65 years and older $25 \%-35 \%$ experience a fall once or more per year. ${ }^{11,12}$ The consequences of falls are well documented and involve a negative impact on mortality, morbidity and quality of life and hence on the health care costs for older people. ${ }^{13-19}$ Estimates suggest that in Europe, 25 billion euros per year are spent on the medical and social care related to fall injuries in older people (aged $\geq 65$ years). ${ }^{20}$ As a consequence of a fall, older people can experience psychological difficulties such as fear of falling, decreased self-efficacy, physical activity avoidance and self-restriction, all of which may negatively influence their ability to live at home. ${ }^{21,22}$

A critical factor affecting the severity of fall consequences in older people is the time spent lying on the floor/ ground. ${ }^{23,24}$ Lying on the floor due to a fall event, particularly for $\geq 1$ hour, is associated with higher mortality rates and hospital admissions, serious injuries and consequent care home admissions. ${ }^{23-25}$ This is why receiving prompt assistance after a fall is very important. A fall detection or alerting device may immediately alert designated individuals or emergency services. ${ }^{26,27}$ Therefore, the use of technology for fall detection or alerting is very relevant in order to avoid life-threatening conditions and to support active, safe and self-determined living at home.

However, improper and infrequent use of fall detection or alerting devices in community-dwelling older people has been reported. ${ }^{24,28-33}$ This is not surprising, as a great number of devices have been developed without sufficiently considering the needs and preferences of older people themselves as the end users. ${ }^{34}$ Dissatisfaction and difficulties with the device may result in using it less often or not using it at all. Moreover, many devices currently available on the market, such as watches and bracelets, require manual activation of the alert. ${ }^{33}$ This becomes impossible when a person loses consciousness or loses the ability to activate the alarm due to injury. In addition, older people sometimes remove such devices during sleep and will consequently be without the possibility to alert.

Hence, considering users' needs and preferences in the development of health-related technologies may promote their daily use of the fall detection and alerting devices. Involving users and exploring their needs may facilitate a comprehensive understanding of aspects linked to feasibility, usability or practical aspects related to daily life. ${ }^{35,36}$ User involvement allows improvements in handling and in the level of acceptance and hence facilitates long-term usage of health-related technologies. ${ }^{36-41}$
Therefore, the aim of this study was to involve communitydwelling older people in device design of a fall detection sensor, including its smartphone application, through the evaluation of the mock-up. A mock-up is a model similar to the prototype, which is not yet fully operational. Thus, with this study, the prototype can be developed according to needs, preferences, feasibility and practical aspects related to its daily use. The research question was what are the needs and preferences of community-dwelling older people regarding a wearable fall detection sensor and its smartphone application during the design and mock-up stage?

\section{Patients and methods Design}

A qualitative descriptive study was conducted using focus group interviews to involve community-dwelling older people in the development of a fall detection device. The definition of user involvement referred to the well-known classification of consultation, collaboration and user control. ${ }^{42,43} \mathrm{We}$ chose the level of consultation, meaning that insight regarding needs and preferences gained from the target users informed our decision-making process in the development of the fall detection device. This low level of involvement was considered appropriate because for the first time, researchers from electronic and communication technology and researchers from nursing science worked from the very beginning together with target users.

We planned the approach based on the theoretical framework for user involvement, the "medical device technology development process", from Shah et al. ${ }^{44}$ The health-related context of this framework made it suitable for the underlying study. The framework suggests various methods of involvement, possible target users for involvement and the following four stages of involvement: 1) idea generation and concept development, 2) device (re-)design and prototype development, 3) prototype testing involving in-house and trials in the real field, and 4) device deployment in the market and user feedback. This study refers to stage II. Stage I was carried out previously without user involvement based on our practical experiences as nurses, our exchange with nursing practice, our interdisciplinary discussion with engineers from electronic and communication technology and evidence in the literature. Stages III and IV will occur as the next steps.

\section{Sample and recruitment}

Participants were recruited via eight seniors' associations, one municipal agency for senior citizens and two ambulant health care institutions, utilizing convenience sampling. ${ }^{45}$ 
All these organizations were located in the Canton of Bern, Switzerland. A seniors' association, which is organized on a regional/national level, provides a forum for discussion and exchange of information and gives a voice to seniors in the society. The municipal agency is responsible for handling the concerns of retired people on a local level, in order to promote their quality of life and independent living. In ambulant health care institutions, health care professionals and care laypersons are providing services in order to maintain and promote the well-being of older people on a regional level. These institutions were chosen for pragmatic reasons, as the data collection took place at the Institute of Nursing Science, which is located in the city of Bern.

The researchers contacted the management of these organizations and inquired if they would support recruitment for the study and act as gatekeeper. A gatekeeper works closely with the researcher and ensures access to the study population. If management agreed to support recruitment, paper-based and/or electronic flyers were distributed within the organization through face-to-face contact, email or a display. The flyer was focused upon the importance of the study, study timeline and possible interview dates, participants' tasks, inclusion criteria, registration information, ethical considerations and information regarding the research team.

Study registration occurred online or via reply card. The online link was provided in the study flyer. The reply card, which was one part of the study flyer, was sent via mail to the Institute of Nursing Science. Participants were responsible to register themselves. Once registered for the study, information regarding date and venue of the interview along with consent for participation was sent to the participants via mail by the researcher. The inclusion criteria consisted of living in the community, living alone or with a partner, being aged 75 years or older, being Swiss German/German speaking and being able to give written and oral informed consent. The exclusion criteria were use of a wheelchair and living in a nursing home or an assisted living facility.

\section{Data collection}

A semistructured interview guideline was used to stimulate and thematically structure the focus group discussion. It was developed by the research team and focused on the needs, preferences, feasibility and practical aspects concerning design and functions that were relevant for the prototype. Additionally, in accordance to Krueger and Casey, ${ }^{46}$ the following five stages for focus group interviews were adhered to: 1) opening question, 2) introductory section, 3) transition question, 4) key questions and 5) concluding question (Supplementary material). In the "Introduction" section, in order to facilitate discussion, the following materials were handed out to the participants: two mock-ups of the bodyworn fall detection sensor (a bendable and a rigid model, $6 \times 3 \times 0.7 \mathrm{~cm}$ ), a copy of the screenshots showing the three smartphone application screens and four patch patterns for fixation of the sensor on the body (Figure 1).

One researcher (FJST) demonstrated, using the abovementioned material, the function and planned usage of the fall detection device, in accordance to the information in Figure 1. It was indicated that the sensor was intended to be fixed on the torso with a patch and that the sensor should be wearable for $>24$ hours and during personal hygiene (taking a shower/bath). The researcher emphasized that this information was the starting point of the focus group interview. The participants should then critically discuss and think about their needs, preferences as well as feasibility and practical aspects when conceiving that they would use this fall detection device in their daily life. In order to describe the sociodemographic characteristics of each participant, a short self-administered questionnaire was handed out at the end of the focus group interview. The interview guideline was pilot tested in the first focus group interview, resulting in minor adaptations regarding the structure of the "Introduction" section (order of information given to the participants). No questions required modification.

In July 2014, three semistructured focus group interviews were conducted at the Institute of Nursing Science. In these interviews, the participants consisted of nine, eight and five older people. Each focus group interview was audio recorded and lasted on average 100 minutes. The first and second authors carried out the interviews. No one else was present during the interviews except the participants and the researchers. One researcher acted as a moderator (FJST), and the other researcher acted as an assistant moderator (SB). The moderator led the discussion by posing open-ended questions, thereby encouraging the participants to elaborate on their views, and by ensuring that the discussion between the participants was pertinent to the topic. The assistant moderator prepared the focus group discussion (room and material), provided support to participants (eg, location, beverages and lavatory) and observed the interview in order to discuss the course of the interview with the moderator.

\section{Data analysis}

A qualitative descriptive analysis was applied using deductive coding. ${ }^{47}$ This data analysis approach is appropriate 


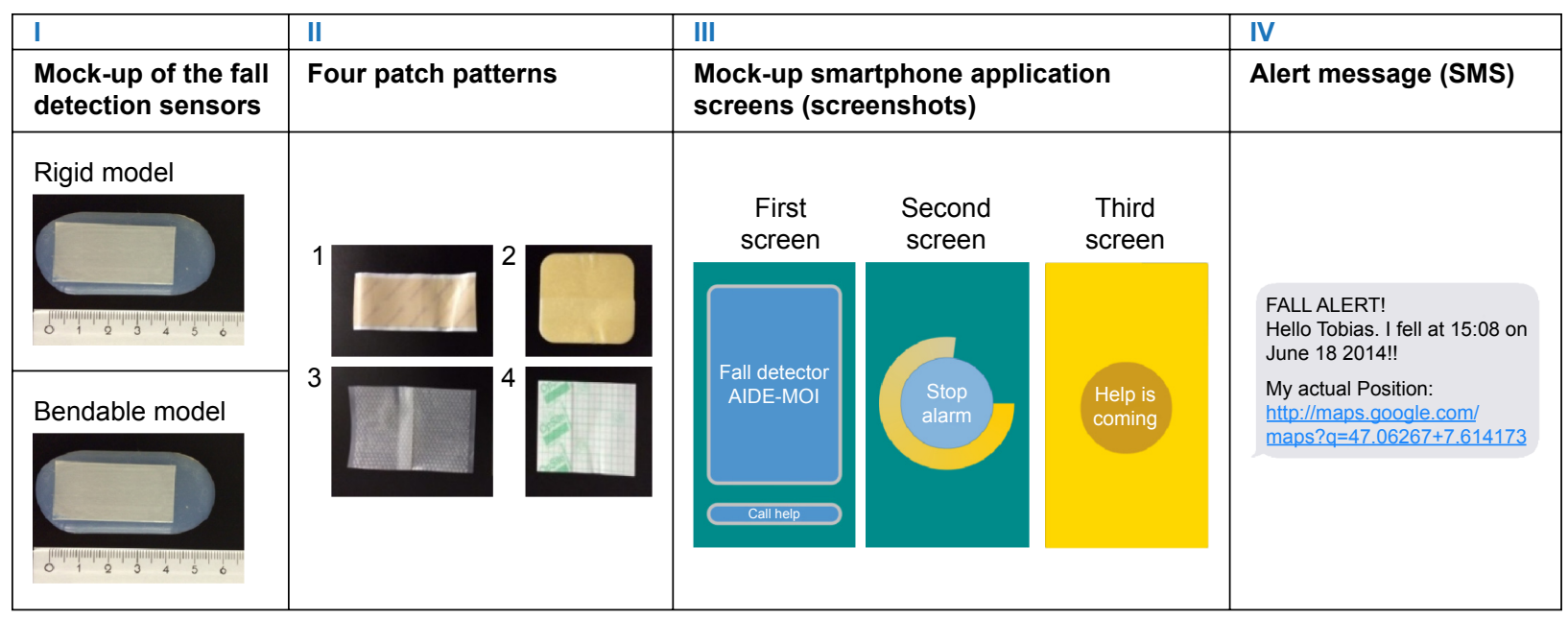

Description

» The fall detection device was developed in cooperation between nursing researchers and researchers from electrical and communication engineering, both from the University of Applied Sciences in Switzerland. Researchers from electrical and communication engineering developed (in their laboratory) the mock-up of the fall detection device.

" The waterproof fall detection device, wearable for $>24$ hours, is targeted for community-dwelling older people.

" The size of the mock-up of the fall detection sensors was $6 \times 3 \times 0.7 \mathrm{~cm}$ with a weight of $10 \mathrm{~g}$.

"A rigid and bendable mock-up of the fall detection sensor was suggested in order to understand which one fits best the needs of the target users (I).

" Four patch patterns were handed out to the participants so that they could visually and tactilely decide what kind of patch they would prefer for fixing the sensor on the body. The choice of patterns was carefully selected by the research team in order to take into account the needs of sensitive skin (II).

" A colored copy of the screenshots showing the three smartphone application screens along the alerting process (III) and the content of the alert message was distributed to each participant (IV).

V

\section{Planned guidelines for the fall detection device}

1. Fall detection sensor is fixed by a patch on the torso.

2. Fall detection sensor is connected via Bluetooth to a smartphone application, which has to be in a range of 8-10 m. When a fall has occurred, the application will open automatically (III, first screen). An alert may be stopped according to an individually adjustable timeframe, illustrated by a closing cycle (III, second screen). As soon as the alert is sent to the contact persons, the application window changes and indicates that help is coming (III, third screen).

3. Additionally: an alert may also be emitted manually by its user (III, second button on first screen).

4. An alert is emitted, indicating the location (GPS) of the fallen person, which is automatically transmitted via SMS successively to predefined contact persons until one person answers the alert (IV, alert message).

Figure I Mock-up fall detection sensor, mock-up smartphone application and their functioning.

Abbreviations: GPS, Global Positioning System; SMS, short message.

for studies aiming for a descriptive summary of the data. ${ }^{47}$ Hence, in accordance to the aim of the underlying study, precise and specific feedback regarding the fall detection sensor and smartphone application under development was obtained. Prior to data analysis, a deductive coding system was developed (FJST, SB and SH) utilizing the themes addressed in the interview guideline during focus group discussion, as listed in Table 1.

The data analysis was conducted in the following seven steps:

1. Transcription of the interviews was combined with a first analysis by deductively assigning the text passages to the corresponding codes of the coding system (using software programs $\mathrm{f}^{\circledR}{ }^{\circledR}$, Microsoft Word $^{\circledR}$ and Excel $\left.^{\circledR}\right)(\mathrm{SB})$.

2. The assignments were checked by the first author (FJST). Differences in the assignments of text passages were discussed until agreement was reached (FJST and SB).

3. Two researchers independently summarized the informational content of the interview text assigned to the deductive codes (FJST and SB).

4. The summarized informational content of both versions was critically compared and discussed, and an integrated version was approved (FJST and SB). 
Table I Deductive coding system

\begin{tabular}{lll}
\hline $\begin{array}{l}\text { Sensor }- \text { needs and preferences } \\
\text { related to }\end{array}$ & $\begin{array}{l}\text { Smartphone - needs and } \\
\text { preferences related to }\end{array}$ & $\begin{array}{l}\text { App - needs and preferences } \\
\text { related to }\end{array}$ \\
\hline Color & Operating distance & Design colors/information \\
Size/shape & Triggering/alerting process & Option "stop alert" \\
Weight & Messaging in context of alerting & Option "need help" \\
Material & Contacts of alert & Use (feasibility and practicability) \\
Body location & Use (feasibility and practicability) & \\
Duration of wearing & & \\
Fixation on body & & \\
Use (feasibility and practicability) & & \\
\hline
\end{tabular}

5. Steps $1-4$ were critically reviewed by a third researcher (SH), ensuring accuracy and that no critical findings were omitted. Later, this critical review was discussed until agreement was reached, which resulted in minor changes (naming of the deductive codes) (FJST, SB and $\mathrm{SH})$.

6. Similarly, codes were summarized into categories and subcategories (FJST and SB). For each subcategory, the most salient phrases were selected as quotes, which adequately represented the content of the subcategories contained in the interview data.

7. The categories and subcategories were discussed in the research team, which resulted in minor modifications regarding their final, appropriate wording (FJST, SB, SH, RJGH and JMGAS).

\section{Ethical approval}

According to Swiss legislation, the study protocol was submitted to the responsible local Swiss ethical board (Ethical Committee of the Canton of Bern). In June 2014, the ethical board decided (Z020/2014) that this study was beyond the responsibility of the Swiss Federal Act on Research Involving Human Beings. This study was conducted in compliance with the protocol, the current version of the Declaration of Helsinki, the ICH-GCP or ISO EN 14155 (as far as applicable), as well as with all national legal and regulatory requirements. Written and oral informed consent was obtained prior to focus group interview participation. No company partner was involved in this study in order to ensure that device development would be driven primarily by the needs of the end users.

\section{Results}

A total of 22 participants were included. As listed in Table 2, the mean age was 80 years (standard deviation 4.5). A total of 14 participants lived alone and 16 participants required no assistance in daily living. Further characteristics are listed in Table 2.

The analysis of needs, preferences, feasibility and practical aspects regarding the design and functions of the mock-ups resulted in two categories and four subcategories, which are described later.

\section{Fall detection sensor - needs and preferences}

The participants welcomed the idea of a body-worn and waterproof fall detection sensor. The following needs and preferences related to the fall detection sensor were identified.

\section{Size, shape, color, weight and material}

The preference for the bendable sensor mock-up was unanimous. Its size (Figure 1) was largely acceptable; however, some participants stated that they would need a thinner one, as it would be more adaptable/comfortable to the body. Others felt that the size should be defined primarily from a technical point of view in order to ensure reliability.

For some participants, the transparent color of the presented mock-up sensor was suitable, while others were

Table 2 Participants' characteristics $(\mathrm{N}=22)$

\begin{tabular}{ll}
\hline Characteristics & Participants (N=22) \\
\hline Age (years), mean (SD) & $80(4.5)$ \\
Age (years), min-max & $75-89$ \\
Gender, $\mathrm{n}(\%)$ & \\
$\quad$ Female & $18(82)$ \\
$\quad$ Male & $4(18)$ \\
Living alone, $\mathrm{n}(\%)$ & $14(64)$ \\
No assistance in daily living, $\mathrm{n}(\%)$ & $16(73)$ \\
History of falls, $\mathrm{n}(\%)$ & $10(45)$ \\
Experiencing fear of falling, $\mathrm{n}(\%)$ & $9(41)$ \\
Mobile/smartphone use, $\mathrm{n}(\%)$ & $8(36)$ \\
Internet use at home, $\mathrm{n}(\%)$ & $13(59)$
\end{tabular}

Abbreviations: min, minimum; max, maximum; SD, standard deviation. 
indifferent. However, other participants preferred an eyecatching color, as per the following statement:

The color is important to me. I am a hobby gardener. If something drops in the shrubs, I can't find it any more. This is why I prefer [it] to be colored, loud and trendy. Such a thing [sensor] isn't visible. [Fg1sII]

In regard to the shape of the sensor, the participants would prefer round, oval or the shape of a blossom. Some participants felt that the sensor should serve its purpose, and others mentioned that it should also serve as a trendy accessory. The weight of the sensor, which was $10 \mathrm{~g}$, was acceptable. The participants compared it with the weight of other assistive devices, such as glasses and hearing aids. The material of the sensor was organic silicon on the surface, which was in general well accepted by the participants due to its softness and it being waterproof as well as due to the practical aspect of it being hygienic because it was washable. However, some were concerned with possible sweating or the feel of its jelly-like surface. In general, the presented mock-up seemed to be well accepted; however, the important issue of reliability remained.

\section{Feasibility and practical aspects related to daily use}

Wearing the sensor on the waist or chest seems feasible and practical, as it would barely affect one's movement and activity. In addition, these body locations are easy to reach and do not require the help of another person. Some participants would prefer to wear the sensor in the brassiere, as this would optimize fixation of the sensor. Other participants raised concerns about a possible negative interaction between the organs and the sensor. They felt that the Bluetooth connection between the sensor and smartphone might be harmful to the functioning of their organs. Thus, they would prefer to wear the sensor on the extremities. The participants emphasized that the issue of wearing might be better explored by actually testing this fall detection sensor under real-life circumstances and over a period of several days or weeks, as per the following comment: "I need to experience it for myself, otherwise, I can't really tell you" [Fg1sII]. The participants had varying ideas regarding the duration of wearing the sensor, ranging from $<24$ hours to more than several weeks. Some seniors emphasized that according to their experience regarding the risk of falling, wearing the sensor during the night is even more important than wearing it during the day. One comment was:

If you have to get up from your bed at night, as every one of us has to do, then, it [the sensor] is even more important than during the daytime. [Fg2sII]
More than once the participants stressed the importance of self-testing in order to be able to evaluate all aspects related to the device's daily use.

The interviewed seniors evaluated four different patches for fixation of the sensor on the body (Figure 1) and emphasized the following: it should be gentle on the skin, simple to manipulate and have good adhesive performance. They consistently favored patches 1 and 3 (Figure 1). Some participants were particularly concerned about the issue of skin hypersensitivity. Hence, they would need alternative ways to fix the sensor on the body.

It stands to reason, you can stick it [patch] on your skin and detach it, but for people with delicate skin it will not work. For me, the main question is how to fix the sensor on without patch? [Fg2sII]

One participant suggested "you should think about a belt with a slit, so you can tie it around the body" [Fg2sII]. For feasibility reasons, the fall detection sensor should be functioning constantly and worn everywhere, including at home, outdoors as well as in the basement or attic, as these places are isolated and it would take time until someone would find a fallen person. Another practical aspect revealed during the focus group discussions was that some participants would prefer to combine the fall detection sensor with a device, which is familiar to them and already used in daily life, such as jewelry (pendant and bracelet) and a personal watch."Personally, I would prefer a bracelet; I am used to it since my youth" [Fg1sII]. In general, the participants agreed that it is crucial that minimal effort be involved in the use of a fall detection sensor and that the range of mobility should not be hindered.

\section{Smartphone - needs and preferences}

The findings showed that the idea of using a smartphone when using the fall detection sensor created some general skepticism among the participants. The following needs and preferences related to the smartphone were identified.

\section{Design (colors and textual content), options "stop alert" and "need help"}

The suggested colors (Figure 1) of the smartphone application were in general accepted by the participants, although some would prefer it to be in red or green. Their suggestion of colors originated from traffic lights, with green indicating "no problem, no alert" and red indicating "problem, alert". However, it was argued that what is more important than the color is that somebody would come to help. The textual content of the application met the needs of the older persons due to it being straightforward and 
readable. The option stop alert was identified as being very important. This would allow a false alert to be stopped and, therefore, not bother a contact person without reason. Not bothering without reason was viewed as very important. The option "need help" allows the manual activation of the alert independent of a fall. This is because there might be situations other than a fall, where receiving help would be important.

\section{Feasibility and practical aspects regarding alerting process}

The participants unanimously stressed that the suggested automatic alert is a clear advantage of this device. It was emphasized that reliable fall detection and alerting is key. The avoidance of false alerts such as during gymnastics, while stumbling or when accidentally bumping the device, is crucial in order to avoid bothering contact persons without reason. However, they were aware that no technology is completely secure. One participant stated "I believe that nothing is $100 \%$, but we should seek the optimum" [Fg2sII]. Once a fall alert has been emitted via smartphone application, the interviewees consistently preferred acoustic signals regarding the process of the alert transition and the confirmation of it by the contact person. This would allow them to be informed without looking at the smartphone, which might be impossible after a fall.

From my point of view this is significant, if perhaps I fall in the kitchen and this device [smartphone] is in the living room. I won't be able to look at it. Then, I am lying on the floor and I am thinking; hopefully it works. [Fg2sII]

Furthermore, the participants suggested a melody instead of a spoken signal. The melody should be louder during alert transmission and as soon as the alert is confirmed, the melody should continue to occur but more quietly. During the night time, this process should include a blinking light. The participants suggested to also send an email when sending an alert via short message (SMS).

The participants had clear ideas about how to choose the contact person in case of a fall. The primary criterion was the availability of the person. It was emphasized that relatives should always be one of the contact persons. Even if they are not able to assist, they should at least be informed that a fall had occurred, as they might be able to organize assistance. Other contact persons could be neighbors because they could provide quick assistance. However, it could not be taken for granted that a neighbor would want to be included as a contact person or that they would be available, particularly if they were younger persons, who are less frequently at home. Health care professionals or a clergyman from the community could also be a contact person. Only as a very last option was the emergency call center mentioned, due to possible high cost in case of a false alert.

A crucial point of discussion was the operating distance $(8-10 \mathrm{~m})$ between the sensor and the smartphone. In particular, participants living in houses with several floors, in apartments with several rooms or in those with regular gardening activities considered this distance as being neither feasible nor practical for daily life.

It is possible to send signals to the moon; hence, more than eight meters should be feasible. This point is important. It should be possible that [the smartphone] remains in one place in the house. [Fg2sII]

In contrast, the participants suggested that this operating distance would be suitable for smaller dwellings, for less mobile people or for people with physical restrictions.

A further aspect of discussion was related to the smartphone itself. Participants expressed their concern regarding the mandatory use of a smartphone when using this fall detection sensor. Few participants reported having experience in using a smartphone. They mostly assumed that a smartphone is difficult, that its different functions are unclear, that one should have it constantly in mind and switched on, and that it must be charged regularly. The preferred solution of many participants was to not use a smartphone at all and instead have a sensor that directly transmits the alert SMS to the predefined contacts. Moreover, having one device is more practical than having two devices. "The more devices you need, the more difficult it is for us aged people" [Fg3sII]. However, participants mentioned that it is important to develop such a device, as future generations will probably not have any difficulties with using a smartphone. Once again, the participants stressed that self-testing is important in order to explore the device thoroughly. In summary, the participants welcomed the automatic fall detection alert but were doubtful regarding the required operation distance between sensor and smartphone as well as the seemingly challenging use of a smartphone in daily life. Hence, some participants would prefer to solely use a sensor.

\section{Discussion}

\section{Principal findings}

The aim of this study was to explore the needs and preferences of community-dwelling older people by involving them in the device design and mock-up development stage of a fall detection sensor and its smartphone application. Overall, 
the participants largely welcomed the automatic and manual alerting functions of the device, as well as that the sensor was waterproof and served both as a day-time wearable device and night-time wearable device. The sensor mock-up was also well-accepted in regard to its weight and material. The bendable model of the sensor mock-up was consistently preferred. These aspects can therefore be directly considered for prototype development.

The needs and preferences differed regarding the size, shape and color of the sensor mock-up. It was discussed that the sensor prototype should be thinner than the mock-up and that it should be available in different shapes and colors. However, the participants emphasized that requirements regarding the reliability of the sensor should determine its size.

\section{Relationship to current literature}

Although the participants felt that wearing the sensor on the body was practicable, they instead suggested combining it with an item that is normally worn in everyday life. The feasibility of this finding should be considered for the prototype development. However, this could be challenging, as a sensor for automatic fall detection has to fulfill a number of technical requirements, such as remaining in a fixed position on the body in order to detect a fall in a sensitive and specific way. ${ }^{48}$

This might be an issue to consider further as items such as jewelry and watches are very familiar to older people. Familiarity seems to play an important role in designing technologies for older people, as it may promote the acceptance and usage of the technology. ${ }^{49,50}$ Design questions are likely to influence acceptability and practicability, as described in the literature on the development of medical devices. ${ }^{51}$ Hence, ensuring familiarity could be a successful way of making technologies accessible to the world and language of older people. ${ }^{49}$ In order to address older people's need for familiarity, their perspective must be included in the design development of fall detection devices. However, during the last decade, research involving end users has focused mainly on fall detection algorithms. ${ }^{34,52,53}$

The participants had doubts regarding smartphone usage. Several end user participants were not confident in the use and handling of it and suggested the use of a sensor without a smartphone. An aversion to smartphone usage is concordant with Abbate et al, ${ }^{54}$ who developed a smartphone-based fall detector for older people attached to the belt. They found that their participants were pessimistic regarding using this device in daily life. A review on "challenges, issues and trends in fall detection systems", emphasized that no previous studies suggesting smartphone-based fall detection devices involved older people. ${ }^{55}$

Difficulties of older people in the use of smartphones are reported in the literature and are considered as being part of the aging process. ${ }^{56}$ Aging is an ongoing process in which the eyesight, touch sensitivity and cognition often gradually decrease. These functions are particularly crucial in the use of a smartphone. In order to overcome these age-related difficulties, technical solutions are required. Smartphones should remain accessible for the aging population. Moreover, this finding shows that involving end users is highly valuable, as it allows the identification of possible barriers for using a device that is under development and helps to classify future end users. Although the criticism of smartphones is legitimate, using a smartphone for fall alerts offers the advantage of being able to use the same device both indoors and outdoors. ${ }^{48,54}$ In addition, the smartphone represents a sustainable device with the potential for future development.

Currently, the use of smartphones as a fall detection device presents a possible barrier; however, in the long-term, smartphone usage will steadily increase among older people. This suggests that in the upcoming years, an increasing number of older people will be familiar with it. ${ }^{57}$ In order to promote this trend, it is important that smartphone developers seriously consider these age-related declines, such as eyesight and touch sensitivity, in the development of smartphones.

As the participants were involved only in the design and mock-up stage, their needs and preferences regarding smartphone usage remain hypothetical until they have tested it. The results of this finding highlight the necessity of older persons' involvement in the next stage of device development. Sensor prototype testing in the real field must entail carefully developed training and support for communitydwelling older people in regard to smartphone usage.

Criticism of smartphones may not be limited solely to the handling of them as participants emphasized their need for being mobile when using such a device. The distance between the sensor and the smartphone is limited due to reliability aspects. As sustaining physical activity and engagement in social life are crucial for active aging, there is a need for being mobile when using a fall detection device. ${ }^{6,58}$ Moreover, independence is described as one of the key factors for older people in the use of technologies. ${ }^{59}$ There are several implications of this finding for the prototype development and for the real field trial. First, technical solutions are required in order to extend the reliable distance between the sensor and the smartphone. Second, alternate ways of transmitting the data to the device should be considered. Third, depending upon 
the technical feasibilities, the training of the older people in the upcoming stage must provide information regarding the management of sensor-to-smartphone radius in daily life. Fourth, in the real field trial, it will be important to explore which end user group might benefit the most from this kind of fall detection device.

A very relevant finding was the repeated emphasis on real-life testing, both in regard to the sensor and to the smartphone. This reveals the positive attitude that end users have regarding their involvement. Furthermore, it demonstrates the adequacy of the applied theoretical framework, which recommends involving the end users in all four steps of device development. ${ }^{44}$

The needs and preferences from the perspective of the involved older people were quite homogenous regarding the mock-up sensor and its smartphone application. This seems surprising as older people are described as being a highly heterogeneous age group. ${ }^{60}$ However, this can be considered as a sign of data saturation, as the possibility to obtain any additional new information had been reached. ${ }^{61}$ It might also have been attributable to the included sample, which may have consisted of individuals who were interested in exploring technologies.

\section{Strengths and weaknesses}

Some limitations should be considered when interpreting the findings. In this study, end users were not involved in the first stage of device development (idea generation and concept development). Through involving end users starting instead at the second stage, we saved resources during the first stage by drawing upon our available interdisciplinary expertise, which consisted of nursing researchers, engineers and a former geriatric medicine nurse. Moreover, discussing possible technological solutions without a mock-up might have been overwhelming for older people, especially those who were less familiar with current technological developments. ${ }^{37,62}$

The convenience sampling is a limitation of the study. It is possible that our sample consisted of older people, who were more motivated, rather than those who were at high risk of falling or those who were more resistant toward technology. This self-selection bias is an ongoing challenge in interview-based research. ${ }^{45}$ The sampling strategy was utilized due to difficulties in recruiting community-dwelling older people for research involvement. Bridgelal et $\mathrm{al}^{37}$ and Shah and Robinson ${ }^{36}$ described the challenges of user involvement in research, but their focus was limited to researchers and industry.
The rigor of the analysis was enhanced by conducting it at different levels with three members of the research team. The primary focus on manifest content during analysis reinforces the trustworthiness of results. ${ }^{47,63}$

\section{Further research}

Based on the findings of this study, the fall detection device prototype will be developed by the research team. In accordance with the underlying theoretical framework, users will be reinvolved in stage III and will test the fall detection sensor prototype in real life.

\section{Conclusion}

This study findings show that older people, as end users, are able to contribute in the mock-up design stage in the development of a fall detection device, by indicating what really matters to them. The exploration of their needs and preferences, along with their input into the feasibility and practical aspects of the device, reveals the value that userinvolvement has for researchers and engineers, especially in guiding development of the device.

The study revealed that this wearable, waterproof sensor for fall detection and alerting is feasible, although the shape, color, size and fixation of the sensor should be modified during the development of the prototype. Several of the participants did not feel comfortable with the use of smartphones. Therefore, careful training and support of participants in smartphone usage during real-life testing will be crucial. Participants indicated that the limited reliable distance for fall detection and alerting between sensor and smartphone should be extended, as it would restrict them in their daily activities.

This study also indicates that older people's perception of activity, independence and familiarity should be considered in the development of a device, as it may influence the acceptance and usage of a fall detection device. These influencing aspects can only be revealed when end users' perspectives are involved. As emphasized by the participants, user involvement in the third stage, the prototype real field testing stage, is necessary in order to go beyond the hypothetical considerations of the second stage. Based on these findings, the prototype of the fall detection device can be developed with a "need-driven" focus.

\section{Acknowledgments}

We are thankful to the study participants for their engagement and accorded time. We are grateful to Tannys Helfer from the Bern University of Applied Sciences, Bern, Switzerland, 
for her linguistic support. This work was supported by the Bern University of Applied Sciences, Switzerland (grant number 14118DPT).

\section{Disclosure}

The authors report no conflicts of interest in this work.

\section{References}

1. WHO. Number of People over 60 Years Set to Double by 2050; Major Societal Changes Required. 2015. Available from: http://www.who. int/mediacentre/news/releases/2015/older-persons-day/en/. Accessed October 23, 2015

2. Jacobzone S, Oxley H. Ageing and Health Care Costs. Internationale Politik und Gesellschaft; 2002:1. Available from: http://library.fes.de/ pdf-files/ipg/ipg-2002-1/artjacobzone-oxley.pdf. Accessed December 1, 2016.

3. WHO. The World Health Report. 2008. Available from: http://www. who.int/whr/2008/whr08_en.pdf. Accessed January 22, 2016.

4. Nowossadeck E. Demografische Alterung und Folgen für das Gesundheitswesen [Demographic aging and health consequences]. In: $G B E$ kompakt [GBE compact]. Berlin: Robert Koch-Institut; 2012;3(2):1-8. German.

5. BAG. Bericht Gesundheit 2020 - Die gesundheitspolitischen Prioritäten des Bundesrates [The health policy priorities of the Swiss Federal Council]; 2013. Available from: http://www.bag.admin.ch/gesundheit 2020/index.html?lang=de. Accessed January 22, 2016. German.

6. WHO. Active Ageing - A Policy Framework; 2002. Available from: http://apps.who.int/iris/bitstream/10665/67215/1/WHO_NMH_ NPH_02.8.pdf. Accessed December 1, 2016.

7. WHO. Policies and Priority Interventions for Healthy Ageing. 2012. Available from: http://www.euro.who.int/__data/assets/ pdf_file/0006/161637/WHD-Policies-and-Priority-Interventions-forHealthy-Ageing.pdf. Accessed January 22, 2016.

8. Thomson S, Figueras J, Evetovits T, et al. Economic Crisis, Health Systems and Health in Europe: Impact and Implications for Policy. 2014. Available from: http://www.euro.who.int/_data/assets/ pdf_file/0008/257579/Economic-crisis-health-systems-Europe-impactimplications-policy.pdf?ua=1. Accessed January 22, 2016.

9. Hahn S, Richter D, Beck M, Thilo FJS. Panorama Gesundheitsberufe 2030 Projektbericht [Panorama health care professions 2030: A project report]. Available from: https://www.gesundheit.bfh.ch/fileadmin/wgs_upload/ gesundheit/6_forschung/Panorama_Gesamtbericht_Schlussbericht.pdf. Accessed December 1, 2016. German.

10. Lamb SE, Jorstad-Stein EC, Hauer K, Becker C. Development of a common outcome data set for fall injury prevention trials: the Prevention of Falls Network Europe consensus. J Am Geriatr Soc. 2005;53(9): $1618-1622$.

11. BFS. Gehvermögen und Stürze [Walking capabilities and falls]; 2013. Available from: http://www.bfs.admin.ch/bfs/portal/de/ index/themen/14/02/01/key/07/05.html. Accessed August 23, 2013. German.

12. WHO. Global Report on Falls Prevention in Older Age. 2007. Available from: http://www.who.int/ageing/publications/Falls_prevention7March. pdf. Accessed April 10, 2014.

13. Centers for Disease Control and Prevention. Falls among Older Adults: An Overview. 2012. Available from: http://www.cdc.gov/homeandrecreationalsafety/falls/adultfalls.html. Accessed August 23, 2013.

14. Hanley A, Silke C, Murphy J. Community-based health efforts for the prevention of falls in the elderly. Clin Interv Aging. 2011;6:19-25.

15. Gründler BM. Sturzprävention für Senioren und Seniorinnen [Prevention of falls with seniors]; 2006. Available from: http://www.bfu.ch/German/ haus/senioren/protektoren/Documents/0610_Sturzpraevention_de.pdf. Accessed August 23, 2013. German.
16. Hester AL, Wei F. Falls in the community: state of the science. Clin Interv Aging. 2013;8:675-679.

17. Stenhagen M, Ekstrom H, Nordell E, Elmstahl S. Accidental falls, health-related quality of life and life satisfaction: a prospective study of the general elderly population. Arch Gerontol Geriatr. 2014;58(1): $95-100$.

18. Tuunainen E, Rasku J, Jantti P, Pyykko I. Risk factors of falls in community dwelling active elderly. Auris Nasus Larynx. 2014;41(1):10-16.

19. Sartini M, Cristina ML, Spagnolo AM, et al. The epidemiology of domestic injurious falls in a community dwelling elderly population: an outgrowing economic burden. Eur J Public Health. 2010;20(5):604-606.

20. Turner S, Kisser R, Rogm W. Falls among Older Adults in the EU-28: Key Facts from the Available Statistics. 2016. Available from: https:// eupha.org/repository/sections/ipsp/Factsheet_falls_in_older_adults_ in_EU.pdf. Accessed January 22, 2016.

21. Legters K. Fear of falling. Phys Ther. 2002;82(3):264-272.

22. WHO. What Are the Main Risk Factors for Falls amongst Older People and What Are the Most Effective Interventions to Prevent These Falls? Health Evidence Network; 2004. Available from: http://www.euro.who.int/_ data/assets/pdf_file/0018/74700/E82552.pdf. Accessed February 18, 2014.

23. Lord SR, Sherrington C, Menz HB. Falls in Older People. Risk, Factors and Strategies for Prevention. Cambridge: Cambridge University Press; 2001.

24. Fleming J, Brayne C. Cambridge City over-75s Cohort study c. Inability to get up after falling, subsequent time on floor, and summoning help: prospective cohort study in people over 90. BMJ. 2008;337:a2227.

25. Ryynanen OP, Kivela SL, Honkanen R, Laippala P. Falls and lying helpless in the elderly. Z Gerontol. 1992;25(4):278-282.

26. Chaudhuri S, Thompson H, Demiris G. Fall detection devices and their use with older adults: a systematic review. J Geriatr Phys Ther. 2014; 37(4):178-196.

27. Ward G, Holliday N, Fielden S, Williams S. Fall detectors: a review of literature. J Assist Technol. 2012;6(3):202-215.

28. Johnston K, Grimmer-Somers K, Sutherland M. Perspectives on use of personal alarms by older fallers. Int J Gen Med. 2010;3:231-237.

29. Johnston K, Worley A, Grimmer-Somers K, Sutherland M, Amos L. Personal alarm use to call the ambulance after a fall in older people: characteristics of clients and falls. J Emerg Primary Health Care (JEPHC). 2010;8(4):1-9.

30. Mann WC, Belchior P, Tomita MR, Kemp BJ. Use of personal emergency response systems by older individuals with disabilities. Assist Technol. 2005;17(1):82-88.

31. Heinbuchner B, Hautzinger M, Becker C, Pfeiffer K. Satisfaction and use of personal emergency response systems. Z Gerontol Geriatr. 2010; 43(4):219-223.

32. Nyman SR, Victor CR. Use of personal call alarms among communitydwelling older people. Ageing Soc. 2014;34(1):67-89.

33. Zingaro S. Nottelefone teils untauglich und überteuert [Emergency phone calls partly ineffectual and overpriced]; 2012. Available from: http://www.srf.ch/konsum/themen/gesundheit/nottelefone-teilsuntauglich-und-ueberteuert. Accessed April 11, 2014. German.

34. Thilo FJS, Hürlimann B, Hahn S, Bilger S, Schols JMGA, Halfens RJG. Involvement of older people in the development of fall detection systems: a scoping review. BMC Geriatr. 2016;16(1):1-9.

35. Shah SG, Robinson I. Medical device technologies: who is the user. Int J Healthc Technol Manag. 2008;9(2):181-197.

36. Shah SG, Robinson I. Benefits of and barriers to involving users in medical device technology development and evaluation. Int J Technol Assess Health Care. 2007;23(1):131-137.

37. Bridgelal Ram M, Grocott $\mathrm{P}$, Weir H. Issues and challenges of involving users in medical device development. Health Expect. 2007; 11(1):63-71.

38. Rodeschini G. Gerotechnology: a new kind of care for aging? An analysis of the relationship between older people and technology. Nurs Health Sci. 2011;13(4):521-528. 
39. Gulliksen J, Goransson B, Boivie I, Blomkvist S, Persson J, Cajander A. Key principles for user-centred systems design. Behav Inform Technol. 2003;22(6):397-409.

40. De Vito Dabbs A, Myers BA, Mc Curry KR, et al. User-centered design and interactive health technologies for patients. Comput Inform Nurs. 2009;27(3):175-183.

41. Facey K, Boivin A, Gracia J, et al. Patients' perspectives in health technology assessment: a route to robust evidence and fair deliberation. Int J Technol Assess Health Care. 2010;26(3):334-340.

42. INVOLVE. Involving the public in NHS, public health, and social care research: Briefing notes for researchers; 2003. Available from: http://www.twocanassociates.co.uk/perch/resources/files/Briefing\%20 Note\%20Final_dat(1).pdf. Accessed December 1, 2016.

43. Morrow E, Boaz A, Brearley S, Ross F. Handbook of Service User Involvement in Nursing \& Healthcare Research. West Sussex, UK: Wiley-Blackwell; 2012.

44. Shah SGS, Robinson I, AlShawi S. Developing medical device technologies from users' perspectives: a theoretical framework for involving users in the development process. Int J Technol Assess Health Care. 2009;25(4):514-521.

45. Robinson OC. Sampling in interview-based qualitative research: a theoretical and practical guide. Qual Res Psychol. 2014;11(1):25-41.

46. Krueger RA, Casey MA. Focus Groups A Practical Guide for Applied Research. London: Sage; 2009.

47. Sandelowski M. Whatever happened to qualitative description? Res Nurs Health. 2000;23(4):334-340.

48. Pannurat N, Thiemjarus S, Nantajeewarawat E. Automatic fall monitoring: a review. Sensors. 2014;14(7):12900-12936.

49. Leonardi C, Mennecozzi C, Not E, Pianesi F, Zancanaro M. Designing a familiar technology for elderly people. Paper presented at: The 6th International Conference of the International Society for Gerontechnology; 2008; Pisa, Tuscany, Italy.

50. Turner P, van de Walle G. Familiarity as a basis for universal design Gerontechnology. 2006;5(3):150-159.

51. Jennifer LM, Elizabeth M, John AC, Beverley JN. Capturing user requirements in medical device development: the role of ergonomics. Physiol Meas. 2006;27(8):R49.
52. Schwickert L, Becker C, Lindemann U, et al. Fall detection with body-worn sensors: a systematic review. Z Gerontol Geriatr. 2013;46(8):706-719.

53. Chen K, Chan AHS. A review of technology acceptance by older adults. Gerontechnology. 2011;10(1):1-12.

54. Abbate S, Avvenuti M, Bonatesta F, Cola G, Corsini P, Vecchio A. A smartphone-based fall detection system. Pervasive Mob Comput. 2012;8(6):883-899.

55. Igual R, Medrano C, Plaza I. Challenges, issues and trends in fall detection systems. Biomed Eng Online. 2013;12:66.

56. Wang Q. The effects of interface design about mobile phones on older adults' usage. In: 4th International Conference on Wireless Communications, Networking and Mobile Computing; 2008:1-4; Dalian, China: IEEE.

57. Deloitte. The Smartphone Generation Gap: Over-55? There's No App for That. 2016. Available from: http://www2.deloitte.com/au/en/pages/ technology-media-and-telecommunications/articles/2014predictionsthe-smartphone-generation-gap.html. Accessed June 7, 2016.

58. WHO. Strategy and Action Plan for Healthy Ageing in Europe, 20122020; 2012. Available from: http://www.euro.who.int/_data/assets/ pdf_file/0008/175544/RC62wd10Rev1-Eng.pdf. Accessed December 1, 2016.

59. Hawley-Hague H, Boulton E, Hall A, Pfeiffer K, Todd C. Older adults' perceptions of technologies aimed at falls prevention, detection or monitoring: a systematic review. Int J Med Inform. 2014;83(6):416-426.

60. Grigsby JS. The meaning of heterogeneity: an introduction. Gerontologist. 1996;36(2):145-146.

61. Fusch PI, Ness LR. Are we there yet? Data saturation in qualitative research. Qual Rep. 2015;20(9):1408-1416.

62. Kujala S. User involvement: a review of the benefits and challenges. Behav Inform Technol. 2003;22(1):1-16.

63. Elo S, Kääriäinen M, Kanste $\mathrm{O}$, Pölkki T, Utriainen K, Kyngäs $H$. Qualitative Content Analysis: A Focus on Trustworthiness. SAGE Open. 2014;4(1):1-10. 


\section{Supplementary material Focus group interview guideline}

1. Start: welcome, introduction to researchers, process, communication forms during focus group interview, data confidentiality, audio recording, questions, informed consent

2. Research project: short overview

3. Opening question

\What are your experiences regarding falls?

4. Introduction

○ Hand out material to participants

○ Describe the fall detection device - sensor; patch; smartphone; smartphone app; charging; and demonstration of its functions.

○ Emphasize: starting point; discuss and think critically about your needs, preferences as well as its feasibility and practical aspects of use in your daily life.

\section{Transition question}

» What are your first impressions when looking at this fall detection device?

○ What is pleasant to you?

○ What is less pleasant to you?

\section{Key questions}

» What do you think regarding the following aspects of the sensor:

- material,

O size,

○ shape,

o weight,
○ color,

- wear, comfort,

○ duration of wearing,

O location of the sensor on the body

"What do you think about the different patches? Which one do you prefer and why?

»What do you thing regarding the smartphone application?

○ Different functions - stop, alarm, manual alerting

○ Colors

○ Comprehension of the text

○ Contact persons

O Short message in case of an alert

"What do you think regarding the smartphone and its use?

○ Distance between sensor and smartphone

» Imagine your everyday life - what do you like and why?

○ while using this sensor

o while using the smartphone application

○ while using the smartphone

7. Concluding question

» What do you think regarding the feasibility of using this fall detection device in your daily life?

»Is there any topic, which we have not yet discussed?

8. Closing: Thank you, short-questionnaire sociodemographic characteristics.

\section{Publish your work in this journal}

Patient Preference and Adherence is an international, peer-reviewed, open access journal that focuses on the growing importance of patient preference and adherence throughout the therapeutic continuum. Patient satisfaction, acceptability, quality of life, compliance, persistence and their role in developing new therapeutic modalities and compounds to optimize clinical outcomes for existing disease states are major areas of interest for the journal. This journal has been accepted for indexing on PubMed Central. The manuscript management system is completely online and includes a very quick and fair peer-review system, which is all easy to use. Visit http://www dovepress.com/testimonials.php to read real quotes from published authors. 